\title{
Effect of stenting on coronary flow velocity reserve: comparison of coil and tubular stents
}

\author{
C J Vrints, M J Claeys, J Bosmans, V Conraads, J P Snoeck
}

\begin{abstract}
Objective-To determine whether coil stents are as effective as tubular stents in improving coronary flow velocity reserve (CFVR) after stent deployment.

Methods-Distal CFVR was measured with a 0.014 inch Doppler guide wire before and after stenting in 33 patients. A coil stent was implanted in 16 patients and a tubular stent was used in 17 patients. Coronary flow velocity within the stent was also recorded during a slow pullback. Results-Following placement of the stents, the percentage diameter stenosis was similar for both the tubular and coil stents (mean (SE) 11 (2)\% $v 13(2) \%$, NS). However, distal CFVR was higher after stenting with a tubular stent compared with a coil stent $(2.46(0.13) v 1.96(0.14)$, p < 0.05). Furthermore, pullback through the stent detected a major flow velocity increase within coil stents but not in tubular stents $(83(24) \% v 5(5) \%, p<0.05)$.

Conclusions-In spite of similar angiographic improvement, placement of coil stents was associated with inferior functional results compared with tubular stents. The flow velocity acceleration within the coil stents suggests the presence of a residual narrowing within the stent, which is not appreciated on angiography. (Heart 1999;82:465-470)
\end{abstract}

Keywords: stents; coronary flow reserve; Doppler guide wires

Correspondence to: Prof Dr Chris J Vrints, Dienst Cardiologie, Universitair Ziekenhuis, Antwerpen, Wilrijkstraat 10, B2650 Edegem, Belgium. email: vrints@uia.ua.ac.be

Accepted for publication 30 March 1999 mains subnormal. ${ }^{2} 910$ This suboptimal increase of distal CFVR after successful angioplasty has been ascribed to ischaemic stunning of the myocardial microvasculature, ${ }^{11}$ to a residual luminal narrowing not appreciated on angiography, ${ }^{12}$ or both. Coronary stenting results in a larger lumen gain than after balloon angioplasty and has been shown to result in a greater increase in distal CFVR. ${ }^{12-16}$

However, even after successful stenting CFVR may remain suboptimal. ${ }^{17}$ This can be caused by impaired microvascular vasodilatation but also by unsatisfactory lumen enlargement after stent placement. Different stent types probably do not have the same properties in the coronary artery. Coil stents are possibly not as effective as tubular stents in restoring the conduit function of the epicardial arteries. Coil stents have a more open design that promotes plaque prolapse and do not always provide a uniform radial expansion of the vessel lumen. This may result in a lower lumen increase and therefore a lower CFVR increase than when a tubular stent is used. In this study we compared the effect of tubular and coil stents on epicardial flow conductance and on distal CFVR.

\section{Methods}

PATIENT POPULATION

The study population comprised 31 patients with stable angina undergoing elective coronary angioplasty and stenting of a non-occlusive major stenosis (diameter stenosis $>50 \%$ ) in a native coronary artery (table 1). All patients had single vessel disease with normal left ventricular function; stenting was performed because of a suboptimal angioplasty result (residual diameter stenosis $>35 \%$ ) or threatened closure (residual diameter stenosis $>50 \%$ with dissection type $\mathrm{C}$ or D). Patients with a myocardial infarction in the perfusion territory of the treated artery, valve disease, congestive heart failure, or notable left ventricular hypertrophy were excluded. Angiographic exclusions included presence of collateral circulation, bypass graft to the target vessel, ostial narrowing inducing wedging of the catheter, distal lesions with small perfusion bed, and lesions not amenable to be crossed by the Doppler coronary guide wire.

Cardiovascular drugs (nitrates, $\beta$ blockers, calcium channel blockers, antiplatelet agents) were continued as clinically indicated. Informed consent was obtained from all patients and the protocol was approved by the institutional ethics committee of the University Hospital of Antwerp.

Values are numbers unless otherwise indicated.

LAD, left anterior descending artery; RCA, right coronary artery; CX, circumflex artery, ACC American College of Cardiology; AHA, American Heart Association. 
Table 2 Quantitative coronary arteriography results

\begin{tabular}{llll}
\hline & $\begin{array}{l}\text { Coil stent } \\
(n=16)\end{array}$ & $\begin{array}{l}\text { Tubular stent } \\
(n=17)\end{array}$ & $p$ Value \\
\hline Minimal luminal diameter (mm) & $0.98(0.10)$ & $1.03(0.08)$ & NS \\
$\quad$ Pre-PTCA & $1.83(0.18)$ & $1.55(0.10)$ & NS \\
$\quad$ Post-PTCA & $2.84(0.12)$ & $2.82(0.09)$ & NS \\
$\quad \begin{array}{l}\text { Post-stent } \\
\text { Interpolated reference diameter (mm) }\end{array}$ & $3.04(0.11)$ & $3.01(0.11)$ & NS \\
Diameter stenosis (\%) & $67.8(2.9)$ & $64.9(2.9)$ & NS \\
$\quad$ Pre-PTCA & $38.5(5.6)$ & $47.7(3.6)$ & NS \\
Post-PTCA & $12.8(2.2)$ & $10.9(1.6)$ & NS \\
Post-stent & & &
\end{tabular}

Values are mean (SE).

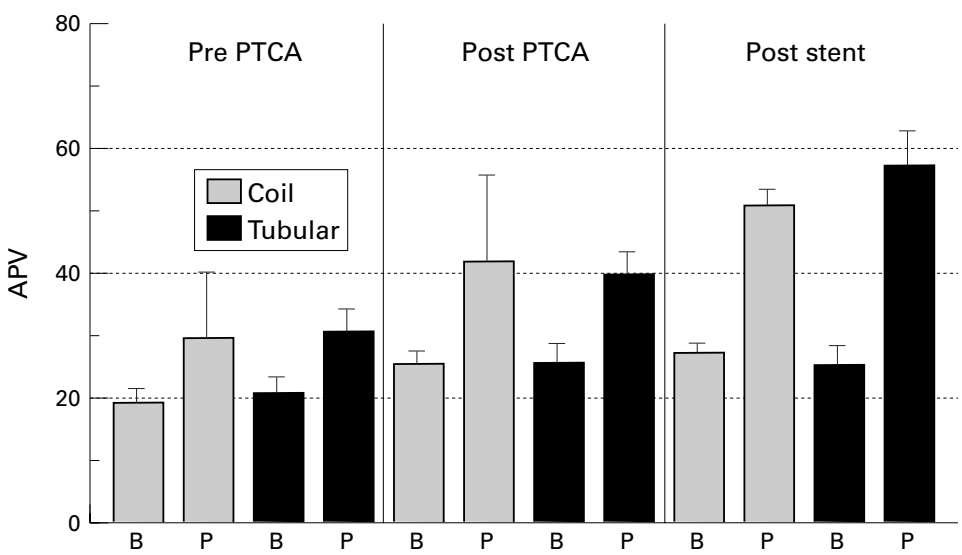

Figure 1 Graph showing the baseline and maximal hyperaemic APV before and after PTCA and after stent implantation.

Table 3 Doppler data

\begin{tabular}{llll}
\hline & $\begin{array}{l}\text { Coil stent } \\
(n=16)\end{array}$ & $\begin{array}{l}\text { Tubular stent } \\
(n=17)\end{array}$ & $p$ Value \\
\hline CFVR & $1.39(0.09)$ & $1.50(0.10)$ & NS \\
$\quad$ Pre-PTCA & $1.63(0.08)$ & $1.83(0.13)$ & NS \\
$\quad$ Post-PTCA & $1.96(0.15)$ & $2.46(0.13)$ & 0.02 \\
$\quad \begin{array}{ll}\text { Post-stent } \\
\quad \text { Reference }\end{array}$ & $2.45(0.15)$ & $2.65(0.19)$ & NS \\
Relative CFVR & $0.76(0.04)$ & $0.91(0.08)$ & 0.09 \\
$\quad \begin{array}{ll}\text { Post-stent } \\
\text { Final CFVR }>2.5 \text { and diameter stenosis }<35 \%\end{array}$ & $2(12.5 \%)$ & $8(47 \%)$ & 0.02 \\
Maximal APV in stent/APV distal from stent & $1.83(0.26)$ & $1.05(0.05)$ & 0.01 \\
$\%$ area stenosis (Doppler) & $37(5)$ & $2(6)$ & 0.01 \\
\hline
\end{tabular}

Values are mean (SE) unless otherwise indicated.

CATHETERISATION PROCEDURE

Angioplasty and stenting were performed after intravenous administration of $10000 \mathrm{U}$ of heparin. A continuous infusion of intravenous isosorbide dinitrate $(0.5 \mu \mathrm{g} / \mathrm{kg} / \mathrm{min})$ was started 15 minutes before the procedure.

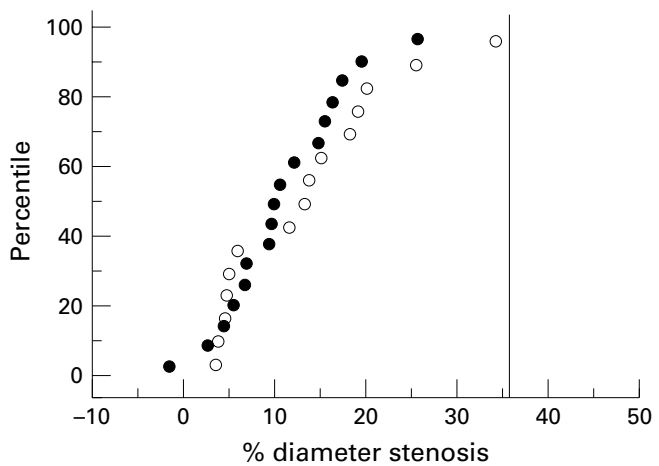

Coronary flow velocity measurements were taken with a 0.014 inch Doppler angioplasty guide wire (FloWire; Endosonics, Rancho Cordova, California, USA) after intracoronary administration of isosorbide dinitrate $(2 \mathrm{mg})$. Continuous flow velocity profiles along with simultaneous ECG and aortic pressure waveforms were displayed on the video monitor and recorded continuously on super VHS videotape.

Distal flow velocities were obtained at least $2 \mathrm{~cm}$ beyond the stenosis at baseline and again during coronary hyperaemia induced by administration of intracoronary adenosine $(18 \mu \mathrm{g}$ bolus for the left coronary artery and $12 \mu \mathrm{g}$ for the right coronary artery). The maximal hyperaemic response after adenosine injection was automatically detected and reported on the video printer. The distal CVFR was calculated as the ratio of the hyperaemic to basal average peak velocity (APV).

Stent delivery was performed using standard techniques. In the patients who where treated with a Gianturco-Roubin stent a one size (0.5 mm larger than the reference diameter) oversized stent was used. Delivery of the Gianturco-Roubin stent was performed with the delivery balloon inflated at low inflation pressure (5 atm) followed with adjunctive high pressure inflations (12-15 atm) with a semicompliant balloon (Viva; Boston Scientific, Maple Grove, Minnesota, USA). Wiktor stents were delivered with inflation of the delivery balloon up to 9-12 atm. Palmaz-Schatz, NIR, and Bestent were manually crimped on a Viva balloon (Boston Scientific) and were delivered with high inflation pressures (15-18 atm). AVE micro I and Multilink stents were delivered with their delivery balloon followed by adjunctive high pressure inflations with a Viva balloon. Stent deployment was assessed with online quantitative coronary arteriography and was optimised with additional balloon inflations until diameter stenosis was lower than $15 \%$.

After an angiographically optimal stent result was obtained, baseline and hyperaemic distal flow velocity data were again measured as before angioplasty 5-15 minutes after the last balloon inflation within the stent. After these

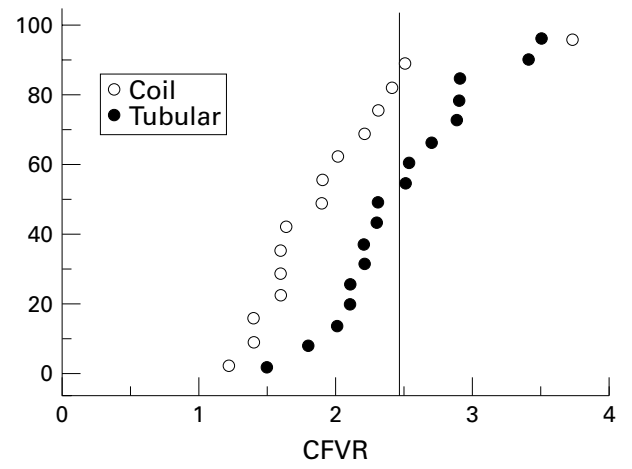

Figure 2 Cumulative distribution of the diameter stenosis (left) and the distal CFVR (right) after placement of tubular and coil stents. All patients have a residual diameter stenosis $<35 \%$ after stent placement (angiographic part of the Doppler end point balloon angioplasty trial Europe (DEBATE) criterion); only two patients with a coil stent have a distal CFVR > 2.5 (Doppler part of the DEBATE criterion), whereas almost half of the patients with a tubular stent meet this criterion. 
measurements were obtained the Doppler guide wire was slowly withdrawn through the stented segment. Baseline coronary blood flow velocity was measured in a reference segment just distally from the stent and was recorded continuously during the slow pullback manoeuvre. If the signal was lost within the stent, as happened frequently, then the Doppler guide wire tip was carefully reoriented towards the lumen and baseline coronary blood flow velocity was measured within the stent after an optimal signal was obtained. Based on the continuity equation, $\%$ area stenosis within the stent was calculated as follows: $(1-$ (APV in reference segment $\div$ maximal APV within the stent)) $\times 100 \%$.

In 19 patients (nine with a coil stent and 10 with a tubular stent) CFVR was also measured in an angiographically normal reference coronary artery. A relative CFVR was calculated as the ratio of the target vessel CFVR and the CFVR in the normal reference artery.

\section{ANGIOGRAPHIC DATA ANALYSIS}

Coronary angiographic images were quantitatively analysed with a computer based cardiovascular angiography analysis system (CAAS II, Pie Medical Data, Netherlands), which was previously described in detail. ${ }^{18}$ End diastolic frames that showed the narrowest stenotic diameter were selected and digitised. The absolute diameter of the lesion ( $\mathrm{mm}$ ) was determined using the non-filled tip of the guiding catheter as a scaling device. Stenosis severity was calculated from the minimal luminal diameter and a computer estimated reference diameter and expressed as $\%$ diameter stenosis. Significant coronary artery stenosis was defined as a luminal diameter stenosis $>50 \%$ in a major epicardial coronary artery or branch. All measurements were made online during the procedure, and the results of the analysis were used for the selection of balloon and stent size and for the optimisation of stent placement.

CORONARY FLOW VELOCITY DATA ANALYSIS

The Doppler guide wire was connected with the $12 \mathrm{MHz}$ pulsed Doppler velocimeter (FloMap, Endosonics) which analysed online Doppler velocity spectra and calculated the temporal average of the instantaneous APV waveform both in baseline conditions and during maximal hyperaemia. CFVR was calculated online from these measurements.

STATISTICAL ANALYSIS

All data are expressed as mean (SE). Demographic, angiographic, and coronary flow variables for the different subgroups were compared by analysis of variance and Scheffe's $F$ test for continuous variables, and by $\chi^{2}$ analysis for categorical variables. A value of $p<0.05$ was considered significant.

\section{Results}

PATIENTS

Age and sex distributions were not different in the two groups. Sixteen patients were implanted with coil stents (Wiktor-stent; Medtronic, Minneapolis, USA $(n=10)$;
Gianturco-Roubin I; Cook, Bloomington, USA $(n=6)$ ), while 17 patients received tubular stents (NIR; Boston Scientific $(n=5)$; Palmaz-Schatz or Crown; Johnson \& Johnson, Miami, Florida, USA ( $\mathrm{n}=7$ ); AVE Microstent 1 ( $n=2)$, Multilink; Guidant, Indianapolis, USA ( $n=1)$; Bestent, Medtronic $(n=2)$ ). Stenting was successful in all patients; all had an uneventful in-hospital outcome with no subacute thrombosis after hospital discharge.

QUANTITATIVE CORONARY ARTERIOGRAPHY

The results of quantitative coronary arteriography are shown in table 2 . Stenting resulted in a notable increase of the minimal luminal diameter and in a significant decrease of diameter stenosis. There was no significant difference in the acute angiographic results between patients stented with a coil stent and those receiving a tubular stent.

CORONARY FLOW VELOCITY DATA

Changes in APV after percutaneous transluminal coronary angioplasty (PTCA) and stenting are shown in fig 1 . After stent placement the peak APV after administration of adenosine was increased in both groups of patients $(\mathrm{p}<0.05 v$ before PTCA). The peak APV after stent placement was higher in patients with a tubular stent than in those with a coil stent but this difference did not reach significance.

The distal CFVR data are given in table 3 and the cumulative distribution of the distal CFVR after stent placement is shown in fig 2 . CVFR was not significantly increased after balloon angioplasty. After placement of a stent CFVR was significantly increased $(p<0.05)$. Distal CFVR was higher in patients with a tubular stent than in patients with a coil stent $(\mathrm{p}<0.05)$

In the coil stent group there was no significant difference in distal CFVR between those patients with a Gianturco-Roubin stent and those with a Wiktor stent $(2.14(0.37) v$ 1.87 (0.12), $\mathrm{p}>0.05)$. In the tubular stent group, patients with an AVE Microstent showed a lower distal CFVR (1.95 (0.15)) than patients given the other types of tubular stent (NIR 2.62 (0.26); Palmaz Schatz or Crown 2.52 (0.24); Multilink 2.53; Bestent 2.35 $(0.15))$. This difference, however, was not significant.

During pullback of the Doppler guide wire through the stent a velocity increase was frequently observed with the coil stents (fig 3). In three patients with a coil stent APV increased twofold or more within the stent, indicating the presence of a residual area stenosis $>50 \%$ after stent placement. A similar increase was never observed in the patients with a tubular stent.

CFVR of the reference vessel was similar in both stent groups. Relative CFVR after stenting was lower in patients with a coil stent than in those with a tubular stent. This difference, however, did not reach significance $(p=0.09)$. 
A

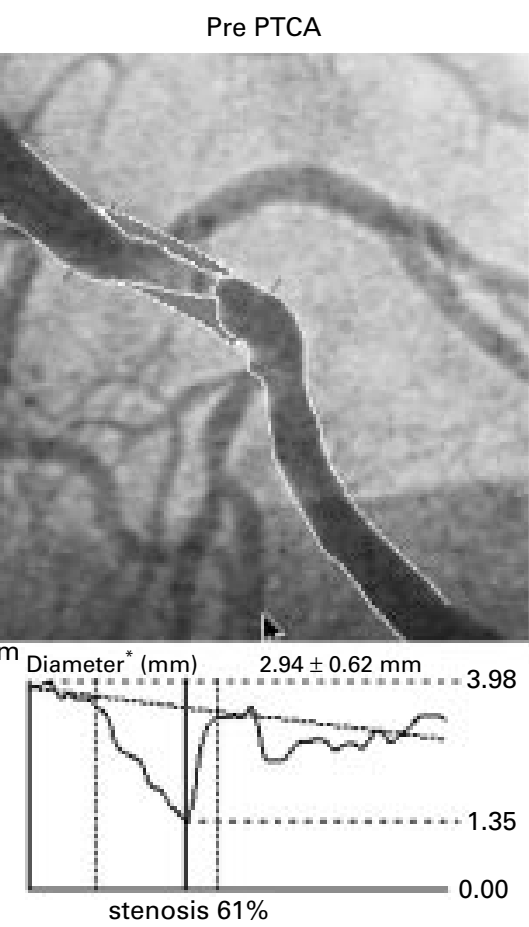

B

LAD Pre PTCA

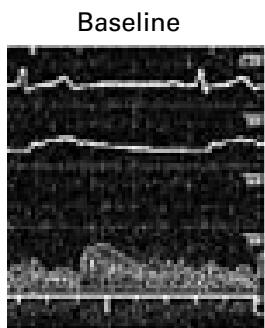

APV: 15

LAD Post stent

Distal from stent

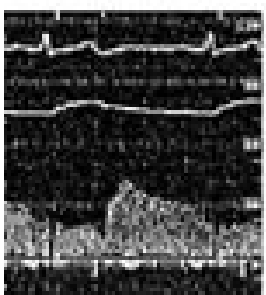

APV: 23

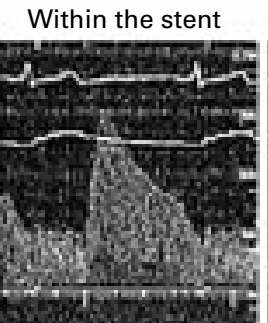

APV: 43
Post PTCA

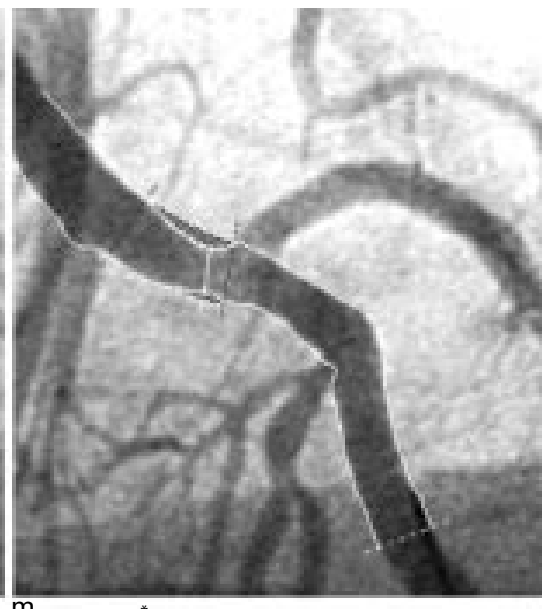

$\mathrm{m}_{\text {Diameter }^{*}(\mathrm{~mm})} \quad 3.33 \pm 0.47 \mathrm{~mm}=4.61$

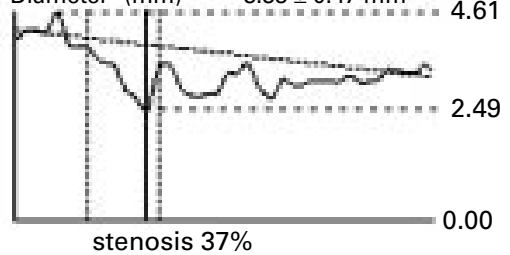

stenosis $37 \%$

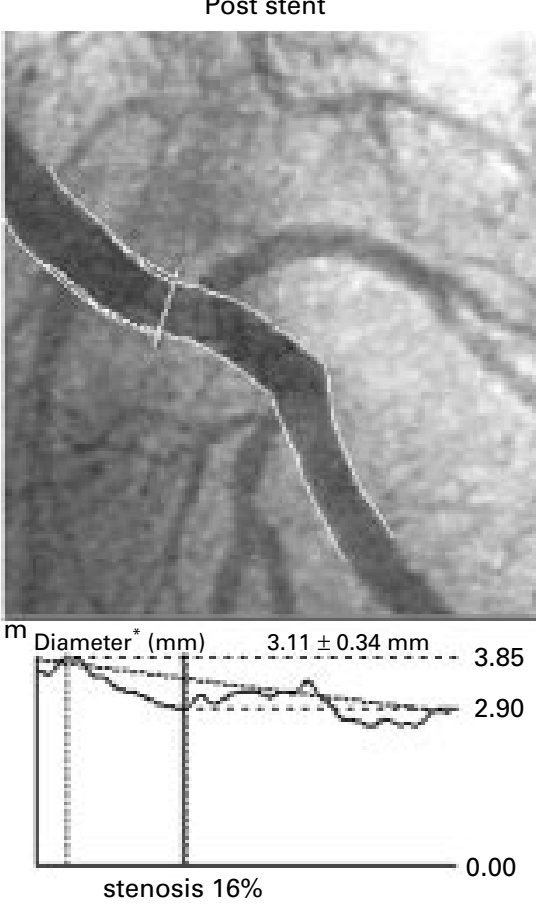

stenosis $16 \%$

Post stent

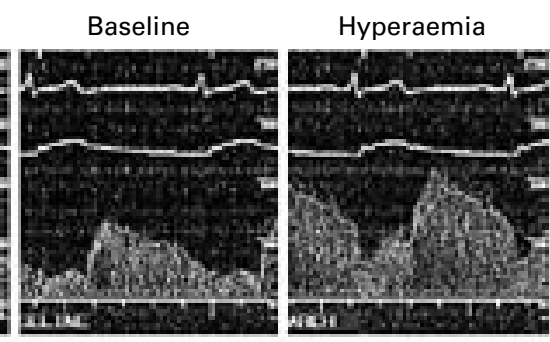

APV: 40 CFVR: 1.9

APV: 21
Post PTCA

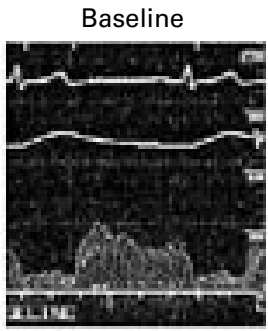

APV: 18

Distal RCA

Post stent

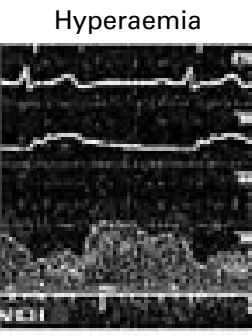

APV: 24 CFVR: 1.4
Baseline

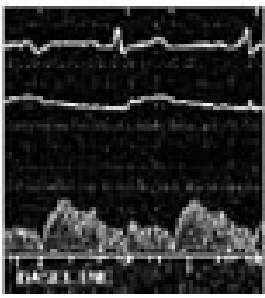

APV: 16
Hyperaemia

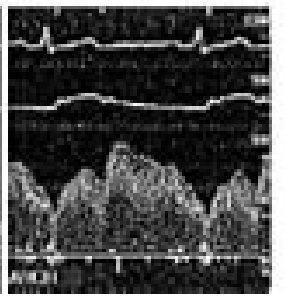

APV: 40 CFVR: 2.5

Figure 3 Angiographic (A) and coronary flow velocity recordings (B) before and after PTCA and after placement of a 3.0 mm Wiktor coil stent in a lesion in the mid-segment of the left anterior descending (LAD) coronary artery. The results of quantitative coronary arteriography and the coronary basal and hyperaemic flow velocity recordings are shown for each stage of the procedure. In addition the coronary flow recordings during pullback through the stent are shown as well as the measurement of the CFVR in the reference vessel (right coronary artery (RCA)). The ECG, aortic pressure, and the spectral flow velocity are shown on each recording. The velocity scale is $0-120 \mathrm{~cm} / \mathrm{s}$. CFVR increases considerably following stent placement but remains lower than in the reference vessel $(1.9 v 2.5)$. During slow pullback an acceleration of the coronary blood flow velocity is observed within the stent, from 23 to $43 \mathrm{~cm} / \mathrm{s}$.

\section{Discussion}

This study shows: implantation of a coil stent leads to a less favourable improvement in coronary blood flow haemodynamics than placement of a tubular stent, even though similar angiographic results are obtained with both types of stents; flow velocity acceleration within coil stents suggests the presence of a residual luminal narrowing within the stent which is not appreciated on angiography; and in more than half of the patients with a tubular stent the distal CFVR remains suboptimal $(<2.5)$, despite excellent angiographic results.

Our study re-emphasises the added value of distal coronary flow velocity measurements for guidance and evaluation of coronary interventions. Although the acute angiographic results after stent implantation were similar in both stent groups, a higher distal coronary flow velocity was observed in the patients with a 
tubular stent than in the patients with a coil stent. Thus, quantitative coronary arteriography alone appears to be insufficient to predict functional improvement following stenting, and additional measurement with Doppler guide wires is necessary for the correct assessment of the functional result of coronary interventions.

TUBULAR VERSUS COIL STENTS

An explanation for the higher distal CFVR in patients receiving tubular stents can in part be found in the observation of a major increase of coronary flow velocity within the coil stents during a slow pullback of the Doppler guide wire. In tubular stents we were never able to detect a significant flow velocity increase. It therefore appears that coil stents do not normalise epicardial flow conductance as well as tubular stents and that a residual stenosis may persist that cannot be detected by coronary arteriography. Since intravascular ultrasound was not routinely performed after stent placement we only can speculate about the mechanisms responsible for the flow velocity increase within coil stents. One explanation could be that inadequate lumen enlargement, caused by plaque prolapse between the struts, leads to a more irregular and less cylindrical lumen than is obtained with tubular stents. This may indeed occur with coil stents such as the Gianturco-Roubin and Wiktor stents, which were used in our study. In addition the irregular lumen within coil stents may possibly promote the occurrence of turbulence, as suggested by the relatively high flow velocity increase within the stent that was observed in some patients. So the residual impairment of flow conductance within coil stents could be both functional and anatomical.

The value of Doppler guided coronary interventions was recently shown in a multicentre prospective study (Doppler end point balloon angioplasty trial Europe (DEBATE)). ${ }^{19}$ Using a combined criterion (postangioplasty CFVR $>2.5$ and presence of an excellent angiographic result $(<35 \%$ diameter stenosis)), a subgroup could be identified with a $16 \%$ restenosis rate at six months, a result similar to that obtained with primary stenting. In our study the DEBATE study criterion ${ }^{19}$ was met only in two patients with a coil stent but in eight patients with a tubular stent. If the prognostic value of this criterion can be extrapolated to stented patients, then this could imply that the clinical outcome after six months follow up would be less with a coil stent than with a tubular stent. Moreover, the presence of flow turbulence within a coil stent may increase platelet activation and aggregation, which may promote subacute thrombosis and possibly also restenosis via an increased release of growth stimulating substances by the aggregating platelets.

CONCOMITANT MICROVASCULAR DYSFUNCTION A distal CFVR $>2.5$ was observed in only eight of the patients with a tubular stent. In the patients with a subnormal CFVR after implantation of a tubular stent a flow velocity increase within the stent was never observed. Also, since high pressure inflations were always used, it can therefore be assumed that the tubular stents were always optimally deployed. Moreover, the relative flow reserve after stenting with a tubular stent was always close to 1.0 in our study, which suggests that in these patients the epicardial flow conductance was completely normal. The subnormal distal CFVR in those patients can therefore only be explained by the presence of a microvascular dysfunction which either existed previously or was acquired during the repetitive ischaemic and reperfusion periods during angioplasty and stenting.

If more than half of the patients with an optimally deployed tubular stent have a subnormal distal CFVR then this implies that the absolute value of the distal CFVR achieved after stent placement is, as a single parameter, insufficient for the physiological assessment of stenting. At least we should normalise it to the distal CFVR measured before the intervention in an angiographically normal reference vessel. Another method for detecting inadequate stent expansion is to search for flow velocity acceleration within the stent by monitoring the blood flow velocity during a slow pullback, as was performed in our study. This method is, however, clinically impractical and carries the risk of moving a stent strut if the guide wire needs to be re-advanced for additional balloon insufflations in order to deploy the stent more optimally. Estimation of fractional flow reserve by measurement of the translesional pressure gradient is another possibility that has been introduced for the assessment of coronary interventions. ${ }^{20-22}$ However, when used alone, this method is possibly not sufficient for the physiological assessment of coronary stenting in all cases, since it assumes the induction of a maximal vasodilatation which is not obtained in more than half of the patients. Combined measurement of distal coronary perfusion pressure and flow velocity therefore appears to be the most optimal method for assessing the restoration of epicardial flow conductance after stenting.

STUDY LIMITATIONS

The limitations of Doppler flow velocity recording and measurement of distal CFVR have been described elsewhere in great detail. ${ }^{23}$ Changes in heart rate and blood pressure may influence measurement of distal CFVR. However, these parameters remained stable during the procedure.

Stent deployment was not assessed by intracoronary ultrasound. Intravascular ultrasound of coil stents is not without hazard ${ }^{24}$ and was not performed in this study. Therefore, we can only speculate about the possible mechanisms of the flow velocity increase observed within the coil stents. However, a flow velocity increase was reported to occur in suboptimally deployed stents ${ }^{25}$; in an ultrasound study comparing Palmaz-Schatz and Wiktor stents the cross sectional and longitudinal symmetry was less with the coil stent than with the tubular stent. ${ }^{26}$ 
Patients were not randomised in the present study and different stent types have been used. The present study reflects, however, our clinical experience with CFVR measurement after stent deployment. Initially coil stents (Gianturco-Roubin I and Wiktor stents) were the ones routinely used in our laboratory. Using this type of stent we were unable to obtain a notable improvement of distal CFVR after stent placement. This was in strong contrast with the reports from other centres which mainly used tubular stents. ${ }^{12-16}$ This experience, coupled with the clinical evidence on the beneficial effect of tubular stents that emerged from the publication of the Benestent trials, have led us to switch toward the routine use of slotted tube stents in our laboratory. Although the patients were not randomised for stent type, they were examined in two consecutive periods, whereby coil stents were routinely used during a first period and tubular stents during a second period.

The absence of follow up data is also a limitation of our study. However, the number of patients is probably insufficient to examine whether the observation of a suboptimal distal CFVR after stent implantation is a predictor for a worse clinical outcome. The prognostic value of distal CFVR after stent implantation is currently under investigation in several large multicentre studies.

CLINICAL IMPLICATIONS

Coronary arteriography is the standard guide for coronary angioplasty and stenting. However, our study re-emphasises that the functional results of coronary interventions cannot be predicted from the findings of coronary arteriography alone.

Although the limitations of coronary arteriography are well known, ${ }^{27}$ new coronary stents are frequently evaluated only by angiographic methods. Our observation that two types of stents produced differing functional results but similar angiographic findings indicates that new stents should also be evaluated for their capacity to restore a normal epicardial flow conductance.

The authors thank Dr M Kern, St Louis University, St Louis, USA for his advice and critical review of the paper.

1 Doucette JW, Corl PD, Payne HM, et al. Validation of a Doppler guide wire for intravascular measurement of coronary artery flow velocity. Circulation 1992;85:1899911

2 Segal J, Kern MJ, Scott NA, et al. Alterations of phasic coronary artery flow velocity in humans during percutaneous coronary angioplasty. $\mathcal{F}$ Am Coll Cardiol 1992;20:276-86.

3 Ofili EO, Kern MJ, Labovitz AJ, et al. Analysis of coronary blood flow velocity dynamics in angiographically normal and stenosed arteries before and after endolumen enlargeand stenosed arteries before and after endolumen enlarge-

4 Segal J. Applications of coronary flow velocity during angioSegal J. Applications of coronary flow velocity during angio-
plasty and other coronary interventional procedures. $A m \mathcal{F}$ plasty and other coronary int

Cardiol 1993;71:17D-25D.
5 Serruys PW, Di Mario C, Meneveau N, et al. Intracoronary pressure and flow velocity with sensor-tip guidewires: a new methodologic approach for assessment of coronary hemodynamics before and after coronary interventions. $A m \mathcal{F}$ Cardiol 1993;71:41D-53D.
6 Di Mario C, Roelandt JR, de Jaegere P, et al. Limitations of the zero crossing detector in the analysis of intracoronary Doppler: a comparison with fast Fourier transform analysis of basal, hyperemic, and transstenotic blood flow velocity measurements in patients with coronary artery disease. Cathet Cardiovasc Diagn 1993;28:56-64.

7 Di Mario C, de Feyter PJ, Slager CJ, et al. Intracoronary blood flow velocity and transstenotic pressure gradient using sensor-tip pressure and Doppler guidewires: a new technology for the assessment of stenosis severity in the catheterization laboratory. Cathet Cardiovasc Diagn 1993; 28:311-19.

8 Chou TM, Sudhir K, Iwanaga S, et al. Measurement of volumetric coronary flow by simultaneous intravascular two-dimensional and Doppler ultrasound: validation in an animal model. Am Heart f 1994;128:237-43.

9 Wilson RF, Johnson MR, Marcus ML, et al. The effect of coronary angioplasty on coronary flow reserve. Circulation 1988;77:873-85.

10 Kern MJ, Deligonul U, Vandormael M, et al. Impaired coronary vasodilator reserve in the immediate postcoronary angioplasty period: analysis of coronary artery flow velocity indexes and regional cardiac venous efflux. $7 \mathrm{Am}$ Coll Cardiol 1989;13:860-72.

11 Uren NG, Crake T, Lefroy DC, et al. Delayed recovery of coronary resistive vessel function after coronary angioplasty. F Am Coll Cardiol 1993;21:612-21.

12 Kern MJ, Dupouy P, Drury JH, et al. Role of coronary artery lumen enlargement in improving coronary blood flow after balloon angioplasty and stenting: a combined intravascular ultround Doppler flow and imaging study. 7 Am Coll Cardiol 1997;29:1520-7.

$13 \mathrm{Ge}$ J, Erbel R, Zamorano J, et al. Improvement of coronary morphology and blood flow after stenting: assessment by intravascular ultrasound and intracoronary Doppler. Int $\mathcal{F}$ Card Imaging 1995;11:81-7.

14 Verna E, Gil R, Di Mario C, et al. Does coronary stenting following balloon angioplasty improve distal cornary flow reserve? [abstract]. Circulation 1995;92(suppl I):I-536.

15 Haude M, Baumgart D, Caspari G, et al. Does adjunct coronary stenting in comparison to balloon angioplasty have an impact on Doppler flow velocity parameters? [abstract] Circulation 1995;92(suppl I):I-547.

16 Haude M, Caspari G, Baumgart D, et al. Comparison of myocardial perfusion reserve before and after coronary balloon predilatation and after stent implantation in patients with postangioplasty restenosis. Circulation 1996;94:28697.

17 Vrints CJ, Claeys M, Bosmans J, et al. Coronary flow after suboptimal PTCA does not lead to normalization of distal coronary flow reserve [abstract]. Circulation 1996;94:I-135.

18 Serruys PW, Foley DP, de Feyter PJ. Quantitative coronary angiography in clinical practice. Dortrecht, Netherlands: Kluwer Academic Publishers, 1994.

19 Serruys PW, di Mario C, Piek J, et al. Prognostic value of intracoronary flow velocity and diameter stenosis in assessing the short and long term outcome of coronary balloon angioplasty: the DEBATE study (Doppler endpoints balloon angioplasty trial Europe). Circulation 1997;96: 3369-77.

20 Pijls NH, van Son JA, Kirkeeide RL, et al. Experimental basis of determining maximum coronary, myocardial, and collateral blood flow by pressure measurements for assessing functional stenosis severity before and after percutaneous transluminal coronary angioplasty. Circulation 1993;87: ous translum $1354-67$.

21 Pijls NHJ, Van Gelder B, Van der Voort P, et al. Fractional flow reserve: a useful index to evaluate the influence of an epicardial coronary stenosis on myocardial blood flow. Circulation 1995;92:3183-93.

22 De Bruyne B, Bartunek J, Sys SU, et al. Relation between myocardial fractional flow reserve calculated from coronary pressure measurements and exercise-induced myocardial ischemia. Circulation 1995;92:39-46.

23 Serruys PW, di Mario C, Kern MJ. Intracoronary Doppler. In Topol EJ, ed. Textbook of interventional cardiology. Philadelphia: WB Saunders, 1994

24 Nicosia A, van der Giessen WJ, Airiian SG, et al. Is intravascular ultrasound after coronary stenting a safe procedure? Three cases of stent damage attributable to ICUS in a tantalum coil stent. Cathet Cardiovasc Diagn 1997;40:265-70.

25 Woscoboinik E, Gordov E, Bousignac G, et al. Detection of suboptimal stent deployement by coronary blood flow velocity measurements in vitro [abstract]. $\mathcal{F} \mathrm{Am}$ Coll Cardiol 1997;29:275A.

26 Werner GS, Schünemann S, Ferrari M, et al. Comparison of slotted-tube and coil stents after high-pressure stent deployement by intravascular ultrasound [abstract]. $\mathcal{f} \mathrm{Am}$ Coll Cardiol 1997;29:275A.

27 Topol EJ, Nissen SE. Our preoccupation with coronary luminology: the dissociation between clinical and angiographic findings in ischemic heart disease. Circulation 1995;92:2333-42. 